\title{
Síndromes neuropsiquiátricas pós-estreptocócicas
}

Post-streptococcal neuropsychiatric syndromes

\author{
Antônio Lúcio Teixeira, Humberto Corrêa, Francisco Cardoso e Leonardo F. Fontenelle
}

\section{Resumo}

Nesta revisão narrativa, o nosso objetivo foi descrever as síndromes neuropsiquiátricas pós-estreptocócicas e discuti-las à luz das evidências científicas atuais sobre os possíveis mecanismos patogenéticos envolvidos. Nos últimos anos, uma série de distúrbios do movimento, como tiques, distonia, parkinsonismo, e transtornos psiquiátricos, como o transtorno obsessivo-compulsivo (TOC) e o transtorno de hiperatividade com déficit de atenção (THDA), vem sendo considerada parte do espectro das manifestações pós-estreptocócicas. O termo PANDAS (acrônimo do inglês: pediatric autoimmune neuropsychiatric disorder associated with streptococcus) foi inclusive cunhado para descrever um subgrupo de pacientes com TOC e tiques que exibe flutuação clínica dos sintomas associada a infecção estreptocócica. Entretanto a análise crítica das evidências clinicolaboratoriais não apóia esse espectro ampliado das manifestações pós-estreptocócicas. Apenas na coréia de Sydenham há evidências consistentes de patogênese mediada por processo auto-imune pós-estreptocócico.

Palavras-chave: coréia de Sydenham, síndrome de Tourette, transtorno obsessivo-compulsivo, PANDAS, infecção estreptocócica.

\begin{abstract}
In this narrative review, our objective was to describe the poststreptococcal neuropsychiatric syndromes and to discuss the possible pathogenetic mechanisms involved in their clinical expression. Recently, several movement disorders, such as tics, dystonia, and parkinsonism, and psychiatric disorders like obsessive-compulsive disorder (OCD) and attention deficit hyperativity disorder (ADHD), are being considered part of a putative spectrum of post-streptococcal infection disorders. The term PANDAS (pediatric autoimmune neuropsychiatric disorder associated with streptococcus) has been introduced to describe a subset of patients with these diagnoses in which onset of symptoms or symptom exacerbations are related to streptococcal infection. However the critical analysis of clinical and laboratory data does not support the hypothesis of an extended spectrum of post-streptococcal neuropsychiatric disorders. Only for Sydenham chorea there is consistent evidence for a post-streptococcal autoimmune mediated pathogenesis.

Key words: Sydenham chorea, Tourette syndrome, obsessive-compulsive disorder, PANDAS, streptococcal infection.
\end{abstract}

Faculdade de Medicina da Universidade Federal de Minas Gerais (UFMG) (Teixeira AL, Cardoso F, Corrêa $\mathrm{H}$ ) Faculdade de Medicina da Universidade Federal Fluminense (UFF) (Fontenelle LF) 


\section{Introdução}

Classicamente a coréia de Sydenham (CS) era considerada a única manifestação neurológica pós-estreptocócica. A CS é um dos critérios maiores para o diagnóstico de febre reumática, doença sistêmica inflamatória que ocorre duas a quatro semanas após a infecção das vias aéreas superiores pelo estreptococo beta-hemolítico do grupo A, o Streptococcus pyogenes. É importante notar que a cardite reumática, caracterizada por disfunções valvares, é a principal e a mais comum manifestação da febre reumática (Stollerman, 2001).

No início da década de 1990, dois grupos independentes descreveram outros transtornos neuropsiquiátricos associados a infecções estreptocócicas. Pesquisadores da Universidade Brown, em Rhode Island, e do Instituto Nacional de Saúde Mental dos Estados Unidos identificaram casos de instalação e/ou exacerbação de tiques e transtorno obsessivo-compulsivo (TOC) após infecções estreptocócicas em crianças (Kiessling et al., 1993; Swedo et al., 1994). Swedo et al. (1998) cunharam, inclusive, o termo PANDAS, acrônimo do inglês pediatric autoimmune neuropsychiatric disorders associated with streptococcal infections, para designar esse grupo de pacientes.

Posteriormente, o espectro de manifestações neuropsiquiátricas pós-estreptocócicas foi ampliado, passando a incluir outros distúrbios do movimento, como parkinsonismo, distonia e discinesias diversas, e alguns transtornos psiquiátricos, como o transtorno de hiperatividade com déficit de atenção (THDA), anorexia nervosa e autismo (Snider e Swedo, 2003; Martino e Giovannoni, 2004).

0 presente trabalho pretende apresentar as síndromes neuropsiquiátricas pós-estreptocócicas e discuti-las à luz das evidências científicas atuais sobre os possíveis mecanismos patogenéticos envolvidos.

\section{Coréia de Sydenham}

A CS acomete preferencialmente crianças em idade escolar, justamente a população com maior freqüência de coIonização e infecção pela bactéria estreptococo beta-hemolítico do grupo A. Nessa faixa etária, a CS é a principal causa de coréia nos países em desenvolvimento, como o Brasil (Mendes et al., 1996). A coréia pode ser definida como movimentos involuntários, arrítmicos, breves, que fluem de uma parte à outra do corpo de forma não-estereotipada.

$\mathrm{Na}$ CS, além de movimentos coréicos, outros sintomas motores estão comumente presentes, como redução do tônus muscular, sacadas hipométricas e disartria (Cardoso et al., 1997; Teixeira et al., 2005). Embora alguns autores defendam a ocorrência de tiques no contexto da CS (Mercadante et al., 1997, 2000), outros questionam a possibilidade de discriminá-los dos movimentos coréicos (Asbhar et al., 2005; Teixeira et al., 2005). Outro distúrbio do movimento observado em alguns pacientes com CS é a bradicinesia, ou seja, a lentificação dos movimentos, que eventualmente preenche os critérios diagnósticos para síndrome parkinsoniana (Teixeira et al., 2003). A ocorrência de bradicinesia em um quadro eminentemente hipercinético é aparentemente paradoxal, mas reflete o comprometimento variável das vias nigroestriatais na CS (Teixeira e Cardoso, 2004).
A partir do trabalho de Swedo et al. (1989, 1993), sintomas psiquiátricos, como labilidade afetiva, hiperatividade e os obsessivo-compulsivos, passaram a ser valorizados na CS. A co-morbidade com TOC foi a mais bem estudada, sendo que diferentes grupos confirmaram a elevada freqüência de TOC na CS (Tabela 1). Foi com base nessa observação clínica que a CS foi proposta como modelo de transtorno neuropsiquiátrico auto-imune (Swedo, 1994).

Tabela 1. Estudos que investigaram a freqüência de sintomas obsessivo-compulsivos (SOC) e de transtorno obsessivo-compulsivo (TOC) em paciente com CS

\begin{tabular}{lccc}
\hline \multicolumn{1}{c}{ Estudo } & $\boldsymbol{n}$ & $\begin{array}{c}\text { Presença } \\
\text { de SOC }\end{array}$ & $\begin{array}{c}\text { Diagnóstico } \\
\text { de TOC }\end{array}$ \\
\hline Chapman et al. (1958) & 8 & $4(50 \%)$ & - \\
Swedo et al. (1989) & 23 & $5(21,7 \%)$ & $3(13 \%)$ \\
Swedo et al. (1993) & 11 & $9(82 \%)$ & $4(36,4 \%)$ \\
Asbahr et al. (1998) & 30 & $21(70 \%)$ & $5(16,7 \%)$ \\
Mercadante et al. (2000) & 22 & $7(31,8 \%)$ & $3(13,6 \%)$ \\
Hounie et al. (2004) & 28 & $2(7,2 \%)$ & $1(3,6 \%)$ \\
Asbahr et al. (2005) & 73 & - & $28(38,4 \%)$ \\
Maia et al. (2005) & 56 & $16(29 \%)$ & $13(23,2 \%)$ \\
\hline \hline
\end{tabular}

$n=$ número de pacientes com CS avaliados.

Há pelo menos quatro linhas de evidência que sugerem a participação de mecanismos auto-imunes na patogênese da CS. A primeira seria a forte associação, em cerca de $90 \%$ dos casos, entre a CS e a cardite reumática. Na cardite reumática está bem estabelecido o envolvimento de processos auto-imunes desencadeados por mimetismo molecular entre antígenos do estreptococo e do tecido cardíaco (Guilherme et al., 2001). A segunda evidência foi obtida inicialmente por Husby et al. (1976), que identificaram anticorpos no soro de pacientes com CS aguda capazes de reagirem com os núcleos caudado e o subtalâmico. Estudos recentes confirmaram a presença de anticorpos antinúcleos da base no soro e no liquor de pacientes com CS aguda (Church et al., 2002, 2003; Singer et al., 2003). Postulou-se, então, que a manifestação da coréia seria decorrente da lesão ou disfunção dos núcleos da base mediada por auto-anticorpos. De fato, estudos de neuroimagem estrutural e funcional demonstraram comprometimento dos núcleos da base na CS (Giedd et al., 1995; Barsottini et al., 2002). Dois estudos sugerem ainda o possível efeito patogênico desses auto-anticorpos antinúcleos da base. Kirvan et al. (2003) descreveram um efeito direto de anticorpos produzidos por clones de linfócitos $B$ de pacientes com CS sobre neurônios em cultura, aumentando o nível de atividade de quinases dependentes de cálcio-calmodulina. Recentemente demonstramos que títulos crescentes de anticorpos antinúcleos da base correlacionaram-se com maiores níveis de cálcio intracelular (após estímulo despolarizante) em células de linhagem neuronial pré-incubadas com o soro de pacientes com CS (Teixeira et al., 2005). 
A terceira linha de evidência seria a alteração de parâmetros imunológicos na CS. Church et al. (2003) demonstraram aumento das citocinas IL-4 e IL-10 no soro e no liquor de pacientes com CS aguda. Ressalta-se que essas citocinas são de perfil Th2, que normalmente encontra-se associado à imunidade mediada por anticorpos. Teixeira et al. (2004) identificaram também aumento das quimiocinas MIG/CXCL9 e IP-10/CXCL10 no soro de pacientes com CS aguda, sugerindo que linfócitos de perfil Th1 também poderiam estar envolvidos no processo. A última evidência consiste na boa resposta clínica à imunossupressão com corticosteróides em casos de CS refratárias ou que desenvolveram complicações com a terapêutica anticoréica convencional baseada em ácido valpróico e neurolépticos (Cardoso et al., 2003; Teixeira et al., 2005).

Portanto há consideráveis evidências acerca da base auto-imune pós-estreptocócica da CS. Nesse sentido, a diversidade de sintomas relacionados à CS refletiria a disfunção imunomediada dos núcleos da base e, conseqüentemente, dos diferentes circuitos frontoestriatais motores e não-motores que desempenham um importante papel na determinação do comportamento humano (Mercadante et al., 2001; Teixeira, Cardoso, 2004).

\section{PANDAS}

Swedo et al. (1998) identificaram um subgrupo de pacientes com TOC e/ou transtorno de tiques, sem critérios para febre reumática, que apresentavam o curso clínico dos sintomas variável conforme a ocorrência de faringites estreptocócicas. Cunharam, então, o termo PANDAS para designar esse subgrupo de pacientes.

Segundo os autores, os critérios para o diagnóstico de PANDAS seriam: 1. diagnóstico de TOC ou transtornos de tiques com base no Manual Diagnóstico e Estatístico de Transtornos Mentais (DSM-IV); 2. início do quadro clínico entre os 3 anos de idade e a puberdade; 3 . curso clínico flutuante caracterizado por início abrupto dos sintomas ou episódios de exacerbação súbita; 4. associação temporal entre as exacerbações e a infecção estreptocócica documentada por elevação nos títulos de antiestreptolisina-O (ASO) e/ou cultura positiva de swab da orofaringe para a bactéria; 5 . associação com sinais neurológicos, como hiperatividade motora e movimentos coreiformes. Na série de 50 casos diagnosticados como PANDAS e relatados por Swedo et al. (1998), 40 apresentavam tiques e 43, sintomas obsessivocompulsivos. Além de exibirem maior superposição de tiques e sintomas obsessivo-compulsivos que os quadros típicos de TOC e transtorno de tiques ou síndrome de Tourette (ST), os casos diagnosticados como PANDAS iniciaram-se, em média, cerca de três anos mais cedo. Como o THDA foi identificado em 40\% dos casos estudados, os autores levantaram a possibilidade de, no futuro, considerar a expansão do conceito de PANDAS no sentido de também incorporar essa condição clínica (Swedo et al., 1998). Contudo esses critérios foram recentemente revisados, mantendo-se o diagnóstico de PANDAS restrito a casos de TOC e transtorno de tiques (Swedo et al., 2004).

Inúmeras críticas, porém, foram realizadas à conceituação de PANDAS (Kurlan, 2004; Kurlan e Kaplan, 2004; Mercadante et al., 2005; Singer e Loiselle, 2003; Teixeira, 2003).
Primeiramente, o diagnóstico PANDAS contempla numa mesma categoria duas condições, TOC e ST, nem sempre superponíveis clinicamente. Curso flutuante e início dos sintomas antes da puberdade ocorrem freqüentemente nos quadros típicos de TOC e ST, portanto não garantiriam especificidade para PANDAS. Infecções estreptocócicas são muito comuns em crianças em idade escolar, sendo difícil estabelecer correlação causal inequívoca com a exacerbação de sintomas no TOC e na ST. Ainda, a definição dos sinais neurológicos motores é genérica. $\mathrm{Na}$ formulação original do diagnóstico de PANDAS não eram definidos o que seriam movimentos coreiformes (Swedo et al., 1998). Isso é extremamente relevante, uma vez que a presença de movimentos coréicos define CS, prescindindo, portanto, de uma nova entidade diagnóstica. Embora na revisão do diagnóstico de PANDAS Swedo et al. (2004) tenham procurado diferenciar coréia de movimentos coreiformes, a distinção foi arbitrária, sem qualquer validação empírica. Finalmente, se PANDAS representasse de fato uma manifestação alternativa de febre reumática, sintomas de cardite e/ou de poliartrite deveriam também ser observados nos casos de PANDAS. Nesse sentido, Snider et al. (2004) realizaram estudo ecocardiográfico em 60 pacientes com diagnóstico de PANDAS e encontraram apenas um caso de insuficiência mitral leve, sendo o restante dos exames sem alterações.

A despeito da fragilidade do conceito PANDAS, vários estudos buscaram obter evidências do envolvimento de mecanismos auto-imunes pós-estreptocócicos na patogênese de um subgrupo de TOC e ST. As principais evidências seriam a identificação de anticorpos antinúcleos da base e a elevação de títulos de ASO em pacientes com TOC e ST (Martino e Giovannoni, 2004; Snider e Swedo, 2003). Embora vários trabalhos tenham apresentado resultados positivos, isto é, tenham demonstrado maiores títulos de anticorpos nesses pacientes quando em comparação com controles, um número significativo de estudos não observou qualquer diferença (Tabelas 2 e 3). A tentativa de correlacionar 0 antígeno $\mathrm{D} 8 / 17$ de linfócito $\mathrm{B}$, possível marcador de febre reumática, com TOC e ST também gerou resultados conflitantes (Chapman et al., 1998; Eisen et al., 2001; Hoekstra et al., 2001; Murphy et al., 1997, 2001; Swedo et al., 1997). O mesmo ocorreu nos estudos com modelos experimentais de infusão, nos núcleos da base de ratos, de soro proveniente de pacientes com ST. Enquanto os trabalhos iniciais mostraram maior freqüência de estereotipias motoras nos ratos que receberam infusão estriatal de soro de pacientes com ST quando em comparação com a infusão de soro de indivíduos controles (Hallett et al., 2000; Taylor et al. 2002), os posteriores, que empregaram métodos automáticos de avaliação das alterações comportamentais, não confirmaram esses dados (Loiselle et al., 2004; Singer et al., 2005a).

Um estudo duplo-cego e controlado com placebo demonstrou benefício da terapêutica imunomoduladora com imunoglobulina intravenosa ou plasmaférese no controle de sintomas obsessivo-compulsivos e tiques em pacientes com critérios diagnósticos de PANDAS, o que poderia sugerir uma base imunológica para o mesmo (Perlmutter et al., 1999). Empregando o mesmo desenho de estudo, Hoekstra et al. (2004), entretanto, não observaram qualquer benefício da terapêutica com imunoglobulina intravenosa em pacientes com transtorno 
Tabela 2. Estudos que investigaram a presença de anticorpos antiestreptocócicos e antinúcleos da base em pacientes com transtornos de tiques

\begin{tabular}{|c|c|c|c|}
\hline Estudo & Número de pacientes/controles & $\begin{array}{l}\text { Anticorpo antiestreptocócico } \\
\text { (ASO) }\end{array}$ & $\begin{array}{c}\text { Anticorpo antinúcleos } \\
\text { da base }\end{array}$ \\
\hline Kiessling et al. (1993) & $45 / 38$ & $=$ controle & $>$ controle $^{a}$ \\
\hline Murphy et al. (1997) & $22 / 21$ & $=$ controle & $=$ controle \\
\hline Singer et al. (1998) & $41 / 39$ & $=$ controle & $>$ controle $^{b}$ \\
\hline Singer et al. (1999) & $41 / 39$ & NA & $>$ controle $^{a}$ \\
\hline Peterson et al. (2000) & $53 / 20$ & $=$ controle & NA \\
\hline Muller et al. (2000) & $36 / 52$ & $>$ controle & NA \\
\hline Cardona et al. (2001) & $150 / 150$ & $>$ controle & NA \\
\hline Morshed et al. (2001) & $81 / 67$ & $>$ controle & $>$ controle $^{b}$ \\
\hline Muller et al. (2001) & $25 / 25$ & $>$ controle & NA \\
\hline Wendlandt et al. (2001) & $20 / 21$ & NA & $>$ controle $^{c}$ \\
\hline Church et al. (2003b) & $100 / 190$ & $>$ controle & $>$ controle $^{\mathrm{a}}$ \\
\hline Loiselle et al. (2003) & $41 / 38$ & $=$ controle & $=$ controle \\
\hline Hoekstra et al. (2003) & $82 / 83$ & NA & $>$ controle $^{\mathrm{a}}$ \\
\hline Church et al. (2004) & $16 / 150$ & NA & $>$ controle $e^{a, b}$ \\
\hline Pavone et al. (2004) & $22 / 22$ & $=$ controle & $>$ controle $^{\mathrm{a}}$ \\
\hline Singer et al. (2004) & $7 / 15$ & NA & $=$ controle \\
\hline Singer et al. (2005a) & $94 / 43$ & NA & $=$ controle \\
\hline
\end{tabular}

NA = Não-avaliado; adiferença baseada no número de resultados positivos do anticorpo em cada grupo; bdiferença baseada na média dos títulos do anticorpo em cada grupo; 'diferença baseada na análise de componente principal do resultado do Western blot.

Tabela 3. Estudos que investigaram a presença de anticorpos antiestreptocócicos e antinúcleos da base em pacientes com TOC

\begin{tabular}{lccc}
\hline \multicolumn{1}{c}{ Estudo } & Número de pacientes/controles & $\begin{array}{c}\text { Anticorpo antiestreptocócico } \\
\text { (ASO) }\end{array}$ & $\begin{array}{c}\text { Anticorpo antinúcleos } \\
\text { da base }\end{array}$ \\
\hline Kiessling et al. (1994) & $19 / 19$ & NA & $=$ controle \\
Murphy et al. (1997) & $26 / 21$ & $=$ controle & $=$ controle \\
Peterson et al. (2000) & $27 / 20$ & $=$ controle & NA \\
Pavone et al. (2004)* & $22 / 22$ & $=$ controle & $>$ controle \\
Singer et al. $(2004)$ & $8 / 15$ & NA & $=$ controle \\
Dale et al. (2005) & $50 / 140$ & NA & $>$ controle, b \\
Singer et al. $(2005 b)^{*}$ & $46 / 43$ & NA & $=$ controle \\
\hline
\end{tabular}

$\mathrm{NA}=$ Não-avaliado; adiferença baseada no número de resultados positivos do anticorpo em cada grupo; bdiferença baseada na média dos títulos do anticorpo em cada grupo; *estudos que avaliaram pacientes com diagnóstico de PANDAS sem especificar se o quadro subjacente corresponde a TOC ou a transtorno de tiques.

de tiques. Em relação à antibioticoterapia profilática, no sentido de evitar reinfecções pelo estreptococo e, conseqüentemente, recaídas clínicas em pacientes com diagnóstico de PANDAS, os resultados também são contraditórios. $O$ estudo duplo-cego controlado com placebo de uso profilático de penicilina oral em pacientes com diagnóstico de PANDAS não demonstrou benefício na prevenção de recaídas clínicas (Garvey et al., 1999). Outro estudo duplo-cego com azitromicina e penicilina, não envolvendo grupo placebo, observou prevenção de recaídas em pacientes com diagnóstico PANDAS (Snider et al., 2005).

Em síntese, as evidências sobre as bases auto-imunes para o diagnóstico de PANDAS são ainda conflitantes e, portanto, insuficientes para a confirmação da existência de fato de um subgrupo de TOC e/ou ST auto-imune pós-estreptocócica. Nesse sentido, não há justificativas para intervenções terapêuticas imunomoduladoras ou antibioticoterapia profilática para pacientes com TOC/ST, como proposto por alguns autores (Kurlan e Kaplan, 2004; Swedo et al., 2004). De qualquer maneira, o possível papel 
de processos auto-imunes pós-infecciosos no TOC ou na ST enfatiza a relevância de fatores ambientais na patogênese de transtornos neuropsiquiátricos.

\section{Outros transtornos psiquiátricos}

Embora a freqüência de transtorno de THDA seja elevada na CS (Mercadante et al., 2000; Maia et al., 2005) e Swedo et al. (1998) tenham encontrado 40\% de TDAH na série original de casos de PANDAS, não houve grande interesse na investigação de uma possível base auto-imune para esse transtorno. Dois estudos observaram elevados níveis de anticorpos antiestreptocócicos, sobretudo ASO, em pacientes com TDAH (Peterson et al., 2000; Loiselle et al., 2003). Curiosamente, títulos mais elevados de anticorpos correlacionaram-se com maior volume dos núcleos da base: putâmen e globo pálido (Peterson et al., 2000).

Baseando-se no aumento da expressão do marcador D8/17 em pacientes autistas, Hollander et al. (1999) propuseram que o autismo também poderia ser uma manifestação de transtorno neuropsiquiátrico auto-imune pós-estreptocócico. Isso também foi observado numa série de casos de anorexia nervosa (Sokol et al., 2002). Outro trabalho revelou aumento dos títulos médios de anticorpos antinúcleos da base em um grupo de 22 adolescentes com anorexia nervosa quando comparados a controles assintomáticos (Harel et al., 2001). Esses estudos, além de utilizarem marcadores bastante controversos de processo auto-imune pós-estreptocócico, não foram reproduzidos posteriormente.

\section{Outros distúrbios do movimento e doenças neurológicas}

Relatos de caso descreveram vários distúrbios do movimento pós-estreptocócicos, incluindo distonia, discinesias paroxísticas e mioclonias (Dale et al., 2002a,b; DiFazio et al., 1998). Recentemente, o grupo do Hospital Queen Square, de Londres, relatou uma série de 40 crianças com distúrbios do movimento iniciados após infecção estreptocócica, incluindo, além de coréia e tiques motores, distonia, tremor, estereotipias, opsoclono e mioclonias (Dale et al., 2004b). Nessa série de casos, o possível nexo causal foi estabelecido pela manifestação do distúrbio do movimento logo após a infecção estreptocócica e pela detecção dos anticorpos antiestreptocócicos ASO e antiDNAse (Dale et al., 2004b) e, posteriormente, pela identificação de anticorpos antinúcleos da base (Church et al., 2004).

O mesmo grupo investigou a presença de anticorpos antinúcleos da base em pacientes adultos com distúrbios do movimento atípicos em termos clínicos, principalmente distonia (Edwards et al., 2002, 2004a,b). Dos 65 casos avaliados, 42 $(65 \%)$ apresentaram esses auto-anticorpos. Essa elevada fre- qüência no grupo de casos atípicos contrasta-se sobremaneira com a freqüência aproximada de $5 \%$ no grupo de pacientes com distonia idiopática primária (Edwards et al., 2004b; Ramachandran et al., 2002). Esses autores especularam, então, se parte dos distúrbios do movimento atípicos não seria determinada por processo auto-imune pós-estreptocócico, uma vez que os auto-anticorpos detectados seriam marcadores desse processo (Church et al., 2004; Edwards et al., 2004; Martino e Giovannoni, 2004).

Baseando-se também na estratégia de investigação de anticorpos antinúcleos da base, o grupo do Hospital Queen Square descreveu ainda uma série de casos de encefalomielite aguda disseminada (ADEM) (Dale et al., 2001) e outra de encefalite letárgica, condição neurológica rara caracterizada por letargia e parkinsonismo, considerados pós-estreptocócicos (Dale et al., 2004a). Ressalta-se, entretanto, que há consideráveis controvérsias acerca do papel desses anticorpos como marcadores do processo auto-imune pós-estreptocócico, além de várias questões relacionadas à metodologia de detecção dos mesmos (Rippel et al., 2005; Singer et al., 2003, 2004, 2005).

\section{Conclusão}

O espectro clínico de complicações neuropsiquiátricas pós-estreptocócicas foi estendido por uma série de autores além do contexto da CS, passando a incluir outros distúrbios do movimento, como tiques e distonia, e transtornos psiquiátricos, como o TOC. Entretanto a análise crítica das evidências clinicolaboratoriais que apoiariam esse espectro ampliado das manifestações pós-estreptocócicas revela, além de resultados contraditórios, dados tendenciosos. Como exemplo destaca-se a utilização de anticorpos antinúcleos da base como critério suficiente para definir a ocorrência de processo auto-imune pósestreptocócico (Church et al., 2004; Dale et al., 2005). Ressaltase que apenas na CS há evidências consistentes de patogênese mediada por processo auto-imune pós-estreptocócico.

Nesse sentido, não há, até o momento, justificativa para qualquer intervenção terapêutica baseada em antibioticoterapia profilática ou imunomodulação em pacientes com quadros considerados pós-estreptocócicos fora do contexto da CS.

Finalmente, a hipótese de que processos auto-imunes pós-estreptocócicos estejam envolvidos na patogênese de uma série de transtornos neuropsiquiátricos ressalta o papel de fatores ambientais na determinação dos mesmos.

\section{Agradecimentos}

Os autores agradecem o suporte financeiro da Fundação de Amparo à Pesquisa de Minas Gerais (FAPEMIG) e do Conselho Nacional de Desenvolvimento Científico e Tecnológico (CNPq). 


\section{Referências}

Asbahr FR, Garvey MA, Snider LA, Zanetta D, Elkis H, Swedo SE. Obsessive-compulsive symptoms among patients with Sydenham chorea. Biol Psychiatry, 57: 1073-6, 2005.

Asbahr FR, Negrao AB, Gentil V, Zanetta D, Paz JA, Marques-Dias $M J$, et al. Obsessive-compulsive and related symptoms in children and adolescents with rheumatic fever with and without chorea: a prospective 6-month study. Am J Psychiatry, 155: 1122-4, 1998.

Barsottini OG, Ferraz HB, Seviliano MM, Barbieri A. Brain SPECT imaging in Sydenham's chorea. Braz J Med Biol Res, 35: 431-6, 2002.

Cardona F, Orefici G. Group A streptococcal infections and tic disorders in an Italian pediatric population. J Pediatr, 187: 71-5, 2001.

Cardoso F, Eduardo C, Silva AP, Mota CC. Chorea in fifty consecutive patients with rheumatic fever. Mov Disord, 12: 701-3, 1997.

Cardoso F, Maia DP, Cunningham MC, Valença G. Corticosteroid treatment of Sydenham's chorea. Mov Disord, 18: 1374-7, 2003.

Chapman AH, Pilkey L, Gibbons MJ. A psychosomatic study of eight children with Sydenham's chorea. Pediatrics, 21: 582-95, 1958.

Chapman F, Visvanathan K, Carreno-Manjarrez R, Zabriskie JB. Flow cytometric assay for D8/17 B cell marker in patients with Tourette's syndrome and obsessive-compulsive disorder. $\mathrm{J}$ Immunol Methods, 219: 181-6, 1998.

Church AJ, Cardoso F, Dale RC, et al. Anti-basal ganglia antibodies in acute and persistent Sydenham's chorea. Neurology, 59: 227-31, 2002.

Church AJ, Dale RC, Cardoso F, et al. CSF and serum immune parameters in Sydenham's chorea: evidence of an autoimmune syndrome? J Neuroimmunol, 136: 149-53, 2003.

Church AJ, Dale RC, Lees AJ, Giovannoni G, Robertson MM. Tourette's syndrome: a cross sectional study to examine the PANDAS hypothesis. J Neurol Neurosurg Psychiatry, 74: 602-7, 2003b.

Church AJ, Dale RC, Giovannoni G. Anti-basal ganglia antibodies: a possible diagnostic utility in idiopathic movement disorders? Arch Dis Child, 89: 611-4, 2004.

Dale RC, Church AJ, Cardoso F, Goddard E, Cox TC, Chong WK, et al. Poststreptococcal acute disseminated encephalomyelitis with basal ganglia involvement and auto-reactive antibasal ganglia antibodies. Ann Neurol, 50: 588-95, 2001.

Dale RC, Church AJ, Benton S, Surtees RA, Lees A, Thompson EJ, et al. Post-streptococcal autoimmune dystonia with isolated bilateral striatal necrosis. Dev Med Child Neurol, 44: 485-9, 2002a.

Dale RC, Church AJ, Surtees RA, Thompson EJ, Giovannoni G, Neville BG. Post-streptococcal autoimmune neuropsychiatric disease presenting as paroxysmal dystonic choreoathetosis. Mov Disord, 17: 817-20, 2002b.

Dale RC, Church AJ, Surtees RA, Lees AJ, Adcock JE, Harding B, et al. Encephalitis lethargica syndrome: 20 new cases and evidence of basal ganglia autoimmunity. Brain, 127: 21-33, 2004a.

Dale RC, Heyman I, Surtees RA, Church AJ, Giovannoni G, Goodman $\mathrm{R}$, et al. Dyskinesias and associated psychiatric disorders following streptococcal infections. Arch Dis Child, 89: 604-10, 2004b.

Dale RC, Heyman I, Giovannoni G, Church AJ. Incidence of anti-brain antibodies in children with obsessive-compulsive disorder. $\mathrm{Br} \mathrm{J}$ Psychiatry, 187: 314-9, 2005.

DiFazio MP, Morales J, Davis R. Acute myoclonus secondary to group A beta-hemolytic streptococcus infection: a PANDAS variant. J Child Neurol, 13: 516-8, 1998.

Edwards MJ, Dale RC, Church AJ, Giovannoni G, Bhatia KP. A dystonic syndrome associated with anti-basal ganglia antibodies. J Neurol Neurosurg Psychiatry, 75: 914-6, 2004.

Edwards MJ, Dale RC, Church AJ, Trikouli E, Quinn NP, Lees AJ, et al. Adult-onset tic disorder, motor stereotypies, and behavioural disturbance associated with antibasal ganglia antibodies. Mov Disord, 19: 1190-6, 2004a.

Edwards MJ, Trikouli E, Martino D, Bozi M, Dale RC, Church AJ, et al. Anti-basal ganglia antibodies in patients with atypical dystonia and tics. A prospective study. Neurology, 63: 156-8, 2004b.

Eisen JL, Leonard HL, Swedo SE, Price LH, Zabriskie JB, Chiang SY, et al. The use of antibody D8/17 to identify B cells in adults with obsessive-compulsive disorder. Psychiatry Res, 104: 221 . 3, 2001.

Garvey MA, Perlmutter SJ, Allen AJ, Hamburger S, Loungee L, Leonard $\mathrm{H}$, et al. A pilot study of penicillin prophylaxis for neuropsychiatric exacerbations triggered by streptococcal infections. Biol Psychiatry, 45: 1564-71, 1999.

Giedd JN, Rapoport JL, Kruesi MJ, Parker C, Schapiro MB, Allen AJ, et al. Sydenham's chorea: magnetic resonance imaging of the basal ganglia. Neurology, 45: 2199-202, 1995.

Guilherme L, Cunha-Neto E, Tanaka AC, Dulphy N, Toubert A, Kalil $J$. Heart-directed autoimmunity: the case of rheumatic fever. $J$ Autoimmunity, 16: 363-7, 2001.

Harel Z, Hallett J, Riggs S, Vaz R, Kiessling L. Antibodies against human putamen in adolescents with anorexia nervosa. Int J Eat Disord, 29: 463-9, 2001.

Hoekstra PJ, Bijzet J, Limburg PC, Steenhuis MP, Troost PW, Oosterhoff $M D$, et al. Elevated D8/17 expression on B lymphocytes, a marker for rheumatic fever, measured with flow cytometry in tic disorder patients. Am J Psychiatry, 158: 605-10, 2001.

Hoekstra PJ, Horst G, Limburg PC, Troost PW, van Lang N, de Bildt $A$, et al. Increased seroreactivity in tic disorder patients to a 60 $\mathrm{kDa}$ protein band from a neuronal cell line. J Neuroimmunol, 141: 118-24, 2003.

Hoekstra PJ, Minderaa RB, Kallenberg CG. Lack of effect of intravenous immunoglobulins on tics: a double-blind placebocontrolled study. J Clin Psychiatry, 65: 537-42, 2004.

Hollander E, Asch GD, Simon L. B-lymphocyte antigen D8/17 and repetitive behaviors in autism. Am J Psychiatry, 156: 317-20, 1999.

Hounie AG, Pauls DL, Mercadante MT, Campos MC, Shavitt RG, Mathis MA, et al. Obsessive-compulsive spectrum disorders in rheumatic fever with and without Sydenham's chorea. J Clin Psychiatry, 65: 994-9, 2004.

Husby G, van de Rijn I, Zabriskie JB, Abdin ZH., Williams RC. Antibodies reacting with cytoplasm of subthalamic and caudate nuclei neurons in chorea and acute rheumatic fever. J Exp Med, 144: 1094-110, 1976.

Kiessling LS, Marcotte AC, Culpepper L. Antineuronal antibodies in movement disorders. Pediatrics, 92: 39-43, 1993.

Kiessling LS, Marcotte AC, Culpepper L. Antineuronal antibodies: tics and obsessive-compulsive symptoms. J Dev Behav Pediatr, 15: 421-5, 1994.

Kirvan CA, Swedo SE, Heuser JS, Cunningham MW. Mimicry and autoantibody-mediated neuronal cell signaling in Sydenham chorea. Nat Med, 9: 914-20, 2003.

Kurlan R. The PANDAS hypothesis: losing its bite? Mov Disord, 19: 371-4, 2004.

Kurlan R, Kaplan EL. The pediatric autoimmune neuropsychiatric disorders associated with streptococcal infection (PANDAS) etiology for tics and obsessive-compulsive symptoms: hypothesis or entity? Pediatrics, 113: 883-6, 2004. 
Loiselle CR, Wendlandt JT, Rohde CA, Singer HS. Antistreptococcal, neuronal, and nuclear antibodies in Tourette syndrome. Pediatr Neurol, 28: 119-25, 2003.

Loiselle CR, Lee O, Moran TH, Singer HS. Striatal microinfusion of Tourette syndrome and PANDAS sera: failure to induce behavioral changes. Mov Disord, 19: 390-6, 2004.

Maia DP, Teixeira AL, Cunningham MCQ, Cardoso F. Obsessivecompulsive behavior and hyperactivity and attention deficit disorder in Sydenham's chorea. Neurology, 64: 1799-801, 2005

Marques-Dias MJ, Mercadante MT, Tucker D, Lombroso P. Sydenham's chorea. Psychiatr Clin North Am, 20: 809-20, 1997.

Martino D, Giovannoni G. Antibasal ganglia antibodies and their relevance to movement disorders. Curr Opin Neurol, 17: 42532, 2004.

Mendes MF, Andrade LA, Ferraz HB. Coréia: análise de 119 casos. Arq Neuropsiquiatr, 54: 419-27, 1996.

Mercadante MT, Campos MC, Marques-Dias MJ, Miguel EC, Leckman J. Vocal tics in Sydenham's chorea. J Am Acad Child Adolesc Psychiatry, 36: 305, 1997.

Mercadante MT, Busatto GF, Lombroso PJ, Prado L, Campos MC, Valle $R$, et al. The psychiatric symptoms of rheumatic fever. Am J Psychiatry, 157: 2036-8, 2000.

Mercadante MT, Hounie AG, Diniz JB, Miguel EC, Lombroso PJ. The basal ganglia and immune-based neuropsychiatric disorders. Psychiatr Ann, 31: 534-40, 2001.

Mercadante MT, Diniz JB, Hounie AG, Ferrao Y, Alvarenga P, Brotto $\mathrm{S}$, et al. Obsessive-compulsive spectrum disorders in rheumatic fever patients. J Neuropsychiatry Clin Neurosci, 17: 544-7 2005

Morshed SA, Parveen S, Leckman JF, Mercadante MT, Kiss MH, Miguel EC, et al. Antibodies against neural, nuclear, cytoskeletal and streptococcal epitopes in children and adults with Tourette's syndrome, Sydenham's chorea, and autoimmune disorders. Biol Psychiatry. 50: 566-77, 2001.

Muller N, Riedel M, Staube A, Gunther W, Wilske B. Increased streptococcal antibodies in patients with Tourette's syndrome. Psychiatry Res, 94: 43-9, 2000.

Muller N, Kroll B, Schwarcz MJ, Riedel M, Straube A, Lutticken R et al. Increased titers of antibodies against streptococcal M12 and M19 proteins in patients with Tourette's syndrome. Psychiatry Res, 101: 187-93, 2001.

Murphy TK, Goodman WK, Fudge MW, Williams RC, Ayoub EM, Dalal $\mathrm{M}$, et al. B lymphocyte antigen D8/17: a peripheral marker for childhood-onset obsessive-compulsive disorder and Tourette syndrome? Am J Psychiatry, 154: 402-7, 1997.

Murphy TK, Benson N, Zaytoun A, Yang M, Braylan R, Ayoub E, et al. Progress toward analysis of $D 8 / 17$ binding to $B$ cells in children with obsessive-compulsive disorder and/or chronic tic disorder. J Neuroimmunol, 120: 146-51, 2001.

Pavone P, Bianchini R, Parano E, Incorpora G, Rizzo R, Mazzone, Trifiletti RR. Anti-brain antibodies in PANDAS versus uncomplicated streptococcal infection. Pediatr Neurol, 30: 107-10, 2004.

Perlmutter SJ, Leitman SF, Garvey MA, et al. Therapeutic plasma exchange and intravenous immunoglobulin for obsessivecompulsive disorder and tic disorders in childhood. Lancet, 354: 1153-8, 1999

Peterson BS, Leckman JF, Tucker D, Scahill L, Staib L, Zhang H, et al. Preliminary findings of antistreptococcal antibody titers and basal ganglia volumes in tic, obsessive-compulsive, and attention-deficit/hyperactivity disorders. Arch Gen Psychiatry, 57: 364-72, 2000.

Ramachandran V, Church AJ, Giovannoni G, Bhatia KP. Antibasal ganglia antibodies are absent in patients with primary blepharospasm. Neurology, 58: 150, 2002.

Rippel CA, Hong JJ, Yoon DY, Williams PN, Singer HS. Methodologic factors affect the measurement of anti-basal ganglia antibodies. Ann Clin Lab Sci, 35: 121-30, 2005.

Singer $\mathrm{H}$, Loiselle $\mathrm{C}$. PANDAS: a commentary. J Psychosom Res, 55: 31-9, 2003.

Singer H, Giuliano JD, Hansen BH, Hallett JJ, Laurino JP, Benson M, et al. Antibodies against human putamen in children with Tourette syndrome. Neurology, 50: 1618-24, 1998.

Singer HS, Giuliano JD, Hansen BH, Hallett JJ, Laurino JP, Benson M, et al. Antibodies against a neuron-like (HTB-10 neuroblastoma) cell in children with Tourette syndrome. Biol Psychiatry, 46: 775-80, 1999.

Singer HS, Loiselle CR, Lee O, Garvey MA, Grus FH. Anti-basal ganglia antibody abnormalities in Sydenham chorea. J Neuroimmunol, 136: 154-61, 2003.

Singer HS, Loiselle CR, Lee O, Minzer K, Swedo S, Grus FH. Anti-basal ganglia antibodies in PANDAS. Mov Disord, 19: 406-15, 2004.

Singer HS, Hong JJ, Yoon DY, Williams PN. Serum autoantibodies do not differentiate PANDAS and Tourette syndrome from controls. Neurology, 65: 1701-7, 2005a.

Singer HS, Mink JW, Loiselle CR, Burke KA, Ruchkina I, Morshed $S$, et al. Microinfusion of antineuronal antibodies into rodent striatum: failure to differentiate between elevated and low titers. J Neuroimmunol, 163: 8-14, 2005b.

Snider LA, Swedo SE. Post-streptococcal autoimmune disorders of the central nervous system. Curr Opin Neurol, 16: 359-65, 2003.

Snider LA, Sachdev V, MacKaronis JE, Peter M, Swedo SE. Echocardiographic findings in the PANDAS subgroup. Pediatrics, 114: 748-51, 2004.

Snider LA, Loungee L, Slattery M, Grant P, Swedo SE. Antibiotic prophylaxis with azitromycin or penicillin for childhood-onset neuropsychiatric disorders. Biol Psychiatry, 57: 788-92, 2005.

Sokol MS, Ward PE, Tamiya H, Kondo DG, Houston D, Zabriskie JB. $\mathrm{D} 8 / 17$ expression on $\mathrm{B}$ lymphocytes in anorexia nervosa. Am J Psychiatry, 159: 1430-2, 2002.

Stollerman GH. Rheumatic fever in the 21st century. Clin Infect Dis, 33: 806-14, 2001

Swedo SE. Sydenham's chorea: a model for childhood autoimmune neuropsychiatric disorders. JAMA, 272: 1788-91, 1994.

Swedo SE, Rapoport JL, Cheslow DL, Leonard HL, Ayoub EM, Hosier DM, et al. High prevalence of obsessive-compulsive symptoms in patients with Sydenham's chorea. Am J Psychiatry, 146: 246-9, 1989.

Swedo SE, Leonard HL, Schapiro MB, Casey BJ, Mannheim GB, Lenane MC, et al. Sydenham's chorea: physical and psychological symptoms of St. Vitus Dance. Pediatrics. 91: 706-13, 1993.

Swedo SE, Leonard HL, Kiessling LS. Speculations on antineuronal antibody-mediated neuropsychiatric disorders of childhood. Pediatrics, 93: 323-6, 1994.

Swedo SE, Leonard HL, Mittleman B, Allen AJ, Rapoport JL, Dow $\mathrm{SP}$, et al. Identification of children with pediatric autoimmune neuropsychiatric disorders associated with streptococcal infections by a marker associated with rheumatic fever. Am J Psychiaty, 154: 110-2, 1997.

Swedo SE, Leonard HL, Garvey M, Mittleman B, Allen AJ, Perlmutter S, et al. Pediatric autoimmune neuropsychiatric disorders associated with streptococcal infections: clinical description of the first 50 cases. Am J Psychiatry, 155: 264-71, 1998.

Swedo SE, Leonard HL, Rapoport JL. The pediatric autoimmune neuropsychiatric disorders associated with streptococcal infection (PANDAS) subgroup: separating fact from fiction. Pediatrics, 113: 907-11, 2004.

Taylor JR, Morshed S, Parveen S, Mercadante MT, Scahill LM, 
Peterson BS, et al. An animal model of Tourette's syndrome. Am J Psychiatry, 159: 57-660, 2002.

Teixeira AL. Coréia de Sydenham: um modelo de transtorno neuropsiquiátrico auto-imune? Psiquiatr Biol, 11: 133-5, 2003.

Teixeira AL, Cardoso F. Neuropsiquiatria dos núcleos da base: uma revisão. J Bras Psiquiatr, 53: 153-8, 2004.

Teixeira AL, Cardoso F, Maia DP, Cunningham MC. Sydenham chorea may be a risk factor for drug-induced parkinsonism. J Neurol Neurosurg Psychiatry, 74: 1350-1, 2003.

Teixeira AL, Cardoso F, Souza ALS, Teixeira MM. Increased serum concentrations of monokine induced by interferon-y/CXCL9 and interferon- $\gamma$-inducible protein 10/CXCL-10 in Sydenham's chorea patients. J Neuroimmunol, 150: 157-62, 2004.
Teixeira AL, Guimarães MM, Romano-Silva MA, Cardoso F. Serum from Sydenham's chorea patients modifies calcium levels in PC12 cells by a complement-independent mechanism. Mov Disord, 20: 843-5, 2005.

Teixeira AL, Maia DP, Cardoso F. The UFMG Sydenham's Chorea Rating Scale (USCRS): reliability and consistency. Mov Disord, 20: 585-91, 2005.

Teixeira AL, Maia DP, Cardoso F. Vocal tics in Sydenham's chorea. Mov Disord, 20(suppl. 10): S7, 2005.

Wendlandt JT, Grus FH, Hansen BH, Singer HS. Striatal antibodies in children with Tourette's syndrome: multivariate discriminant analysis of IgG repertoires. J Neuroimmunol, 119: 106-13, 2001. 